\title{
Sala de aula invertida: percepções docentes e discentes a partir de um relato de experiência das aulas de Tópicos em Química na Pós-graduação
}

\author{
Augusto G. O. de Freitas*, Caroline Raquel Bender*, Valesca Brasil Irala**, \\ Graziela Carrazzoni dos Santos ${ }^{* * * *}$, Willian da Silva Chaves ${ }^{* * * *}$, Mariane da Rosa Minhos
}

\section{Resumo}

O uso de metodologias ativas tem sido amplamente discutido em todos os níveis de ensino como uma tendência para a superação das aulas em um formato exclusivamente transmissivo e focado no professor, para dar protagonismo aos discentes durante o desenvolvimento didático. A crítica aos modelos tradicionais de ensino não é recente e tem sido amplamente discutida pela comunidade acadêmica; entretanto, para além do aparato teórico mobilizado quando um docente se dispõe a adotar uma metodologia ativa, seja ela qual for, torna-se necessário contrapor os pressupostos do modelo adotado ao que, de fato, é possível operacionalizar em cada contexto específico, com suas próprias características, expectativas e dificuldades, para, a cada nova experiência docente com o uso da metodologia adotada, outros aspectos não previstos pelo aparato teórico serem (re)dimensionados à luz da prática docente. Nesse sentido, este trabalho se configura como um relato de experiência a respeito do uso da metodologia da Sala de Aula Invertida (SAI), na disciplina de Tópicos em Química, em um curso de Especialização

* Doutor em Química, pela Universidade Federalde Santa Maria, Professor da Universidade Federal do Pampa - Unipampa, Brasil. E-mail: agofqmc@gmail.com

* Doutora em Química, pela Universidade Federalde Santa Maria, Professora da Universidade Federal do Pampa - Unipampa, Brasil. E-mail: carolinebender@unipampa.edu.br

*** Doutora em Letras - Linguística Aplicada, pela Universidade Católica de Pelotas, Professora da Universidade Federal do Pampa - Unipampa, Brasil. E-mail: valescairala@unipampa.edu.br

**** Graduada em Bacharel Interdisciplinar em Ciência e Tecnologia e Matemática Licenciatura, pela Universidade Federal do Pampa - Unipampa, Professora substituta da Universidade Federal do Pampa e da educação básica, Brasil. E-mail: carrazzoni.unipampa@gmail.com

***** Graduado em Física Licenciatura, pelo Instituto Federal de Educação, Ciência e Tecnologia Farroupilha, Professor da educação básica, Brasil. E-mail: william.chaves.rs@gmail.com

...*** Graduada em Matemática Licenciatura, pela Universidade Federal do Pampa - Unipampa, Brasil. E-mail: marianeminhos@gmail.com

Recebido em: 06/07/2020 - Aceito em: 09/12/2020

https://doi.org/ 10.5335/rbecm.v4i1.11285

http://creativecommons.org/licenses/by-nc-nd/4.0 
em Ciências Exatas e Tecnologia, ofertado em uma universidade pública no interior do Rio Grande do Sul. O texto do relato apresenta dois focos: no primeiro, o enquadramento docente sobre a experiência e, no segundo, a percepção dos alunos a respeito do modelo SAI, a partir de um questionário com perguntas abertas, respondido ao término da disciplina. Os resultados apontam que, no contexto em questão, ou seja, um curso de especialização lato sensu, foram evidenciados ganhos na aprendizagem dos discentes e as dificuldades pontuais na compreensão dos conteúdos previstos pela disciplina foram equalizadas durante as aulas presenciais. Por sua vez, alguns discentes, ao avaliarem a transposição da SAI, especialmente para o contexto da Educação Básica, embora evidenciem as vantagens do modelo, também apontam alguns desafios, os quais precisam ser equacionados ou minimamente previstos durante cada experiência de ensino, de forma a compreendê-la sempre de maneira situada.

Palavras-chave: metodologias ativas; sala de aula invertida; ensino de Química; percepções.

\section{Introdução}

Muitas mudanças têm sido sinalizadas nas diferentes instituições de ensino no mundo todo, com vistas às demandas emergentes do século XXI, especialmente após o crescimento e popularização da cultura digital sobre a analógica (MENDOZA, 2011). Seguir ensinando por meio de modelos e protocolos empregados há décadas não é razoável frente a esse cenário, uma vez que os novos tempos e a velocidade com que acontecem as mudanças na sociedade também têm impacto nas salas de aula, mesmo quando as instituições mantêm padrões tradicionais, materializando-se em desinteresse de muitos alunos pelos modelos conservadores de ensino na atualidade (OLIVEIRA; ARAUJO; VEIT, 2016). Um exemplo disso é o crescimento mundial dos Massive Open Online Courses (MOOC) para o contexto do ensino superior e do homeschooling, para a Educação Básica (CARBONELL, 2015). Para que as instituições de ensino se adéquem às demandas contemporâneas, não cabe mais crer que um modelo transmissivo que, se outrora rendeu bons resultados, hoje não é mais percebido, de forma geral, como suficiente.

Além disso, a crescente promoção das avaliações externas sistêmicas, nacionais e internacionais, provocam um grande impacto para as instituições, com vistas a estabelecer e regular os padrões de qualidade educacional, desde a educação básica até a pós-graduação, através de diferentes instrumentos (em geral, por meio de testes padronizados em grande escala, os quais, quando têm seus resultados divulgados publicamente, geram um conjunto de debates midiáticos e também na sociedade em geral sobre a qualidade da Educação), tendendo a tensionar para um conjunto mais ou menos difundido de questionamentos sobre os sistemas educativos pior 
avaliados nessa conjuntura, o que tem provocado, sistematicamente, também por essas forças externas, a busca de alternativas para incidir sobre mudanças mais profundas no campo educacional (FERNANDES, 2019; ROSSIT; STORANI, 2010; VIANNA, 2003).

Ainda que sejam necessárias mudanças estruturais mais amplas no que diz respeito aos processos de sala de aula, as metodologias ativas têm se mostrado como um caminho fecundo, já que têm como princípio que o aluno seja sujeito ativo na construção do conhecimento (MACEDO et al., 2018). Nessa condição, o aluno busca informações, reflete, discute, traça estratégias e desenvolve conhecimentos. Portanto, segundo Berbel (2011), entende-se que as Metodologias Ativas se baseiam em formas de desenvolver o processo de aprendizagem, valendo-se de experiências reais ou simuladas (o tanto quanto possível próximas às reais), buscando condições de solucionar, com sucesso, desafios próprios das atividades essenciais da prática social, em diferentes contextos.

Dentro do arcabouço das Metodologias Ativas existem várias estratégias de condução dos processos, como, por exemplo, estudo de caso, peer instruction, design thinking, entre outros (BACICH; MORAN, 2018; CAMARGO; DAROS, 2018). A sala de aula invertida (doravante, SAI), também conhecida por seu termo em língua inglesa, flipped classroom, objeto deste relato de experiência, baseia-se em alterar o paradigma em que o professor expõe e explica o conteúdo em sala de aula e o aluno executa tarefas em casa. No modelo invertido, o aluno se prepara em casa, acessando o conteúdo antes da aula. Na aula, ao invés de audiência cativa, passa-se a discutir, realizar atividades relativas aos conteúdos e intercambiar os conhecimentos adquiridos com os demais atores do processo.

Neste trabalho, relatamos o emprego da SAI na disciplina de Tópicos em Química, em uma turma de pós-graduação lato sensu em Ciências Exatas e Tecnologia. O objetivo deste artigo é apresentar a percepção docente sobre as facilidades e dificuldades dos alunos frente aos conteúdos trabalhados, bem como problematizar a percepção dos discentes sobre a SAI. Nas seções seguintes, inicia-se por uma breve revisão teórica, seguindo pelo relato em si da experiência a partir da perspectiva docente e, por fim, mostra-se a percepção dos alunos a respeito da metodologia, por intermédio de um questionário respondido ao término da disciplina através de da disponibilização das perguntas para os alunos em um arquivo de texto e devolvidas 
ao docente de forma anônima por intermédio de uma das alunas que fez a recolha das respostas.

\section{Breve revisão da literatura sobre a SAl}

Há consenso na literatura em apontar a SAI como uma metodologia ativa inovadora no processo de ensino-aprendizagem. Apresenta-se aqui uma breve revisão da literatura da área, na qual serão discutidos e apresentados alguns trabalhos que, nos últimos anos, foram publicados sobre a SAI em diferentes contextos educativos. Embora eles sejam bastante pertinentes, são apenas um recorte não exaustivo e não foram selecionados a partir de uma base de dados específica.

Conforme Bishop e Verleger (2013), o método da SAI consiste em duas partes: em sala de aula, atividades em grupo e interativas e, fora da sala de aula, orientação individual baseada principalmente no uso de tecnologias digitais. Nesse contexto, Valente (2014) aponta que quando se faz uso dessa metodologia, as instruções e o conteúdo são estudados on-line antes de o estudante ir para a sala de aula, que, por sua vez, passa a ser o espaço para discussão em grupo, realização de atividades práticas, projetos e resolução de problemas.

Bergmann e Sams (2016) são autores que se destacam na conceituação de SAI, pois eles apontam que esta metodologia ativa procura otimizar o tempo em sala de aula e a busca da autonomia dos estudantes. Os estudantes tornam-se protagonistas de sua aprendizagem e o professor assume o papel de mediador, deixando de lado a aula expositiva. Nesse sentido, o professor passa a instigar, em um processo colaborativo, a procura de informações e/ou aprofundamento de conhecimentos dos seus alunos. Essa inversão da sala de aula acontece quando o estudante tem o contato com o conteúdo antes da aula, ou seja, ele lê livros, artigos e assiste videoaulas em casa. Em sala de aula, presencialmente, resolve atividades, ameniza dúvidas, discute e aprofunda aquilo que foi estudado previamente (BERGMANN; SAMS, 2016).

Nesse sentido, a SAI pode aprimorar a interação entre os estudantes e o professor, promovendo um ambiente de aprendizagem em que os estudantes possam ser efetivamente responsáveis pelo seu próprio aprendizado. Além disso, promove uma aprendizagem de base construtivista e oferece uma maneira de o conteúdo ficar permanentemente disponibilizado ao estudante, de modo que ele possa assisti-lo quantas vezes quiser (BERGMANN; OVERMYER; WILIE, 2012). Em contrapartida, 
em casa, o discente estuda em seu próprio ritmo, tendo a opção de pausar o vídeo e reproduzi-lo quantas vezes achar necessário ou, em caso de textos, reler diversas vezes o que não compreendeu. Adicionalmente, o aluno tem acesso ao professor para sanar suas dúvidas ou questionamentos perante o tema proposto, para abordá-las em aula, pois o foco na SAI é voltado à aplicação dos conceitos estudados previamente em casa pelos alunos.

Como destacam Bergmann e Sams (2016, p. 14), “o papel do professor em sala é o de amparar os alunos, não o de transmitir informações”. Desse modo, na SAI, o aluno assume uma postura ativa e, muitas vezes, contribui para a aprendizagem de seus colegas por meio de suas explicações, atuando na ampliação de saberes coletivos. Nessa perspectiva, o estudante, esteja no nível de ensino em que estiver, começa a agir ativamente, como personagem principal na sua aprendizagem, abandonando o papel de espectador que lhe era típico num modelo transmissivo. Sendo o professor um mediador neste processo, necessita-se que ambos atores se organizem em etapas, para que a aula, como um evento didático, ocorra seguindo os procedimentos compreendidos pela metodologia, antes, durante e depois de cada aula (MOREIRA, 2018).

De acordo ao documento Flipped Classroom Field Guide (2014), deve haver, durante a aula presencial, variados questionamentos e resoluções de problemas/ atividades a fim de conduzir o aluno a aplicar e ampliar seus estudos prévios. $\mathrm{O}$ professor deve fornecer um feedback logo após as atividades em sala de aula. Faz parte da avaliação formal do estudante a participação tanto nas atividades online como nas presenciais. Por outro lado, o professor deve fornecer materiais de estudo bem estruturados e planejados.

Segundo Bennet et al. (2012), a utilização dessa metodologia não é fácil de ser operacionalizada, uma vez que não existe um modelo específico para a sua utilização. Por sua vez, Bezerra (2007) destaca a necessidade de atualização da prática docente. É necessário que docentes e discentes evitem a resistência ao desconhecido e entendam que os suportes e dispositivos, tais como computador, celulares, tablets, softwares e demais mídias são ferramentas para auxiliar o processo de aprendizagem.

Na Universidade Escola de Medicina de Indiana (EUA), a pesquisa de Tune, Sturek e Basile (2013), baseou-se na aplicação de aulas invertidas com alunos de pós-graduação, voltadas para a área de Fisiologia. Essa pesquisa demonstrou uma 
melhora no desempenho dos alunos nas avaliações, quando comparadas ao ensino tradicional. Eles atribuíram este resultado aos estudos dos alunos em casa, às respostas aos questionários em sala, bem como às discussões refinadas em sala de aula.

No Brasil, existem algumas pesquisas voltadas ao uso da SAI na pós-graduação, que é o nível de ensino mobilizado neste relato. Podemos citar o trabalho de Sant'ana, Amorim e Melo (2018), em que as autoras propuseram a implementação da sala de aula invertida na disciplina de Introdução ao Campo Educação em Saúde, para a primeira turma do Mestrado Acadêmico da Escola Superior de Ciências da Saúde. As aulas foram organizadas em temas e indicações de filmes pedagógicos, levando a oferta de oportunidades para a prática de trabalhos em grupos e habilidades de comunicação.

Loureiro e Delphino (2017) relataram sua experiência no curso de Especialização em Aprendizagem Significativa e Metodologias Ativas, da Faculdade Flamingo. De modo geral, os autores consideraram a vivência em inverter aulas como bastante construtiva, na qual foram identificados momentos desafiadores, desde o planejamento até a obtenção dos resultados. Os autores ressaltam que houve dificuldades, principalmente, no planejamento da aula, de acordo com o tempo e diferentes circunstâncias.

Um trabalho interessante foi relatado por Pavanelo e Lima (2017), envolvendo a aplicação da SAI em uma disciplina de Cálculo I, com alunos ingressantes em cursos de engenharia do ITA (Instituto Tecnológico de Aeronáutica). A pesquisa foi desenvolvida com os alunos acessando o conteúdo teórico das aulas (teoremas, conceitos, definições, propriedades), antes da aula presencial, por meio de livros e videoaulas, disponibilizados no ambiente virtual da disciplina. Os pesquisadores não produziram suas próprias videoaulas e sim selecionaram cuidadosamente aulas de instituições consagradas no ensino de Cálculo e organizadas de acordo com o conteúdo desenvolvido na disciplina. Em sala de aula, os alunos, em grupos de quatro integrantes, concentravam esforços na resolução de exercícios e também de problemas de aplicação propostos pelos professores. Ao final do trabalho, os autores relataram a ansiedade dos alunos por mudanças no processo de ensino e aprendizagem, bem como a postura dos docentes perante uma metodologia inovadora. Por outro lado, também foi observada a dependência dos alunos em relação à aula expositiva. Outro ponto crítico foi a qualidade do material de apoio escolhido para 
os estudos dos alunos em casa. Os autores destacaram que não foram satisfatórios, devido ao tempo relativamente longo das videoaulas e didática do professor.

Recentemente, Bizolatti e Neto (2018) publicaram um trabalho de revisão com o objetivo de descrever de que forma a sala de aula invertida vem sendo abordada no ensino de Matemática. Embora tenham encontrado alguns trabalhos em áreas próximas, os autores concluíram que a revisão reportada por Pavanelo e Lima (2017) era o único trabalho até o momento, na perspectiva de interesse. Mesmo assim, destacaram que a SAI está servindo de auxílio no processo de ensino e aprendizagem, oportunizando a autonomia do professor e dos alunos.

Lima-Junior et al. (2017) reportam a aplicação da SAI no ensino de Química, com alunos do $3^{\circ}$ ano do ensino médio. Na fase inicial da pesquisa, um ambiente virtual de aprendizagem (AVA) foi criado para inserir as atividades a serem realizadas, bem como servir de canal de comunicação entre professores e alunos. $O$ trabalho consistiu em uma experiência curta, envolvendo o conteúdo de radioatividade. Os autores relataram que criaram seus próprios vídeos, utilizando softwares disponíveis gratuitamente na internet. Ao final da pesquisa, foi aplicado um questionário. Os alunos responderam no questionário que, no momento em que assistiam aos vídeos, registravam perguntas a serem respondidas em aula e que, geralmente, pausavam e retornavam o vídeo sempre que necessário para a boa compreensão dos conceitos. A maioria dos alunos mostrou-se interessada em experimentar a SAI em outras disciplinas, embora não tenha sido consenso entre os participantes que esse método seja mais eficiente do que a metodologia tradicional. Por fim, os autores concluíram que, com o emprego da SAI, houve uma participação mais ativa dos alunos, os quais passaram a fazer colocações mais fundamentadas, críticas e argumentativas nas discussões em sala de aula.

Em 2018, Martins apresentou um produto educacional intitulado Projeto sala de aula invertida de química: uma proposta de sequência didática sobre equilíbrio químico. No projeto, a autora abordou os fundamentos e desafios da utilização da SAI como modelo de ensino. A autora organizou uma sequência didática sobre equilíbrio químico e apresentou um roteiro para elaboração e edição de vídeos. Ao final do projeto, a autora destacou que é possível utilizar a SAI em uma escola pública; porém, será mais difícil colocar o modelo em prática se o estudante (ou escola) não tiver os recursos para acessar os materiais fora da sala de aula. 
Por fim, Talbert (2019) apresenta um conjunto de ferramentas, técnicas e procedimentos possíveis para serem adotados no modelo SAI, bem como alguns passos a respeito do processo, os quais podem ser flexivelmente reinterpretados por cada contexto docente, a fim de gerar experiências inovadoras de ensino que se entendem sempre de maneira situada (BOHN, 2001; DORNELLES, 2008; IRALA, 2016) e não como um receituário tomado de forma acrítica pelos professores. Ainda que sejam recebidas com entusiasmo, as metodologias ativas têm se mostrado, na literatura investigada, a partir de diferentes experiências, permeadas por inúmeros desafios, os quais, muitas vezes, transpõem o âmbito da sala de aula, mas se vinculam às problemáticas sociais e conjunturais mais amplas (AGUIRRE-AGUILAR, 2020). É, portanto, tendo em conta esses aspectos, que será apresentado o relato de experiência na perspectiva docente na próxima seção.

\section{relato da experiência pela percepção docente}

A concepção deste trabalho teve início a partir da construção do plano de ensino da disciplina de Tópicos em Química, do Curso de Especialização em Ciência Exatas e Tecnologia ofertado no Campus Itaqui da Universidade Federal do Pampa (UNIPAMPA), uma instituição multicampi localizada em dez municípios do interior do Rio Grande do Sul. A disciplina consiste em 02 (dois) créditos, sendo cada crédito equivalente a 15 (quinze) horas/aulas e foi realizada no período de maio a julho de 2019, contando com 10 estudantes que cursaram a disciplina e foram aprovados. Dos 10 alunos, 7 eram Licenciados em Matemática, 1 em Física, 1 Bacharel em Ciência e Tecnologia e 1 Bacharela em Engenharia Civil. Logo na primeira aula apresentou-se a metodologia que seria utilizada.

O desenvolvimento das atividades ocorreu com base nos conteúdos e cronograma preestabelecidos no plano de ensino. Ao final de cada aula, indicava-se o conteúdo que seria trabalhado ao longo da próxima semana. Para orientar os trabalhos extraclasse foram elaborados questionários (que serviriam de base para o estudo), disponibilizadas bibliografias (livros e/ou artigos) em formato digital, recomendados sites para acesso a textos ou videoaulas relacionados ao conteúdo. Todos os materiais foram cuidadosamente selecionados, considerando o nível de conhecimento apresentado pela turma. Conteúdos disponibilizados gratuitamente na Internet, por universidades consagradas no ensino de Química, foram selecionados preferencialmente. 
Em sala de aula, realizava-se o extrato da semana, isto é, uma sondagem para averiguar o que foi superado, dentre aqueles conteúdos propostos. A partir daí, as dúvidas ou insuficiências em conhecimentos prévios eram debatidas e trabalhadas dialogicamente entre o professor e os alunos. A aula foi baseada nas discussões que surgiam a partir das dúvidas apontadas. Quando necessário, professores e alunos utilizavam o quadro como ferramenta para auxiliar nas explicações.

Na concepção do Programa de Pós-Graduação em Ciências Exatas e Tecnologia, a disciplina de Tópicos em Química foi pensada como uma espécie de nivelamento dos alunos do curso, haja vista a possibilidade de ingressantes de formações distintas (por exemplo: engenheiros, arquitetos, contadores, farmacêuticos, matemáticos, bacharéis em ciência e tecnologia, entre outros). Em função disso, o conteúdo programático, demonstrado no Quadro 1, proporciona uma abordagem desde os fundamentos gerais e conceitos sobre estrutura atômica até o conteúdo de cinética química.

Quadro 1: Relação de tópicos e respectivos conteúdos trabalhados ao longo da disciplina de Tópicos em Química

\begin{tabular}{|l|l|}
\hline \multicolumn{1}{|c|}{ Tópico } & \multicolumn{1}{c|}{ Conteúdos } \\
\hline Definições de conceitos gerai & Átomos; moléculas; íons; elétron; próton; nêutron. \\
\hline Estrutura atômica & $\begin{array}{l}\text { Histórico da evolução de modelos atômicos; modelos atômi- } \\
\text { cos quânticos, isótopos. }\end{array}$ \\
\hline Tabela periódica & Organização da tabela periódica; propriedades periódicas. \\
\hline Mecânica ondulatória & $\begin{array}{l}\text { Definição de onda eletromagnética; cálculos de energia, } \\
\text { comprimento de onda e frequência. }\end{array}$ \\
\hline Reações químicas e estequiometria & $\begin{array}{l}\text { Tipos de reações química; cálculos estequiométricos; rea- } \\
\text { gentes limitantes e em excesso. }\end{array}$ \\
\hline Ligações químicas & $\begin{array}{l}\text { Definição de ligação química; condições termodinâmicas } \\
\text { para ocorrência de uma ligação química; ligações covalente, } \\
\text { iônica e metálica; interações intermoleculares }\end{array}$ \\
\hline Equilíbrio químico & $\begin{array}{l}\text { Definição de equilíbrio químico; quociente reacional e cons- } \\
\text { tante de equilíbrio; princípio de Le Châtelier. }\end{array}$ \\
\hline Cinética química & $\begin{array}{l}\text { Conceitos de velocidade e ordem reação; métodos de deter- } \\
\text { minação de ordem de reação. }\end{array}$ \\
\hline
\end{tabular}

Fonte: dados da pesquisa (2020).

Os três primeiros tópicos foram parte da mesma aula, na qual se estabeleceu um diagnóstico e percepção a respeito dos conhecimentos prévios dos alunos. Nesse momento foi informado sobre a metodologia de trabalho a ser adotada na disciplina. Como esse foi o primeiro encontro, não havia definição prévia de conteúdo, nem preparação anterior dos alunos para esses temas; então, realizou-se uma revisão, 
seguindo a metodologia expositiva. A partir dessa aula, os conteúdos estabelecidos foram discutidos e materiais foram disponibilizados aos acadêmicos, para se prepararem ao longo da semana.

No Quadro 2 são resumidos os conteúdos abordados e as respectivas dificuldades ou facilidades apresentadas pela turma, a partir da percepção docente. É importante esclarecer que o conceito de percepção aqui adotado é o do antropólogo britânico Tim Ingold (2000), que compreende a atividade perceptiva não como uma operação mental que governa os sentidos de forma difusa antes de conduzir o indivíduo à ação, mas como um movimento intencional e agentivo, permeado pela indissociabilidade mente-corpo, indivíduo-sociedade e natureza-cultura. Nesse sentido, a percepção é, em síntese, intrincada pela ação e não pré-existente a ela, como se advoga nas teorias psicológicas convencionais.

Quadro 2: Relação de conteúdos e suas dificuldades ou facilidades de aprendizagem

\begin{tabular}{|l|l|}
\hline \multicolumn{1}{|c|}{ Conteúdo } & \multicolumn{1}{c|}{ Dificuldades/Facili ades a partir da percepção docente } \\
\hline Conceitos gerais & $\begin{array}{l}\text { Não foram observadas dificuldades significativas. A abordagem envolveu } \\
\text { a recapitulação de conceitos já vistos, em algum momento de sua esco- } \\
\text { larização prévia, por todos. }\end{array}$ \\
\hline Estrutura atômica & $\begin{array}{l}\text { Pequena dificuldade na concepção moderna de átomo. Principal dificu - } \\
\text { dade associada à compreensão de orbital atômico como região do espa- } \\
\text { ço em forma de mapa de densidade eletrônica. }\end{array}$ \\
\hline Tabela periódica & $\begin{array}{l}\text { Pequenas dificuldades na associação de propriedades periódicas com a } \\
\text { estrutura eletrônica de cada elemento. }\end{array}$ \\
\hline Mecânica ondulatória & Facilidade na assimilação dos fundamentos e cálculos. \\
\hline $\begin{array}{l}\text { Reações químicas e } \\
\text { estequiometria }\end{array}$ & $\begin{array}{l}\text { Dificuldades envolvendo relações estequiométricas, que foram facilmente } \\
\text { superadas com atividades presenciais. }\end{array}$ \\
\hline Ligações químicas & $\begin{array}{l}\text { Dificuldades de ressignificação do conceito de ligação por meio da análise } \\
\text { do balanço de forças atrativas e repulsivas e interpenetração de orbitais. }\end{array}$ \\
\hline Equilíbrio químico & $\begin{array}{l}\text { Facilidade nas operações matemáticas e pequenas dificuldades relativas } \\
\text { ao estado de equilíbrio - como se atinge e como o sistema responde a } \\
\text { perturbações desse estado. }\end{array}$ \\
\hline Cinética química & $\begin{array}{l}\text { Facilidades na parte matemática e dificuldades de conexão desta parte } \\
\text { com fenômenos cinéticos experimentais. }\end{array}$ \\
\hline
\end{tabular}

Fonte: dados da pesquisa (2020)

Com exceção da primeira, todas as demais aulas foram realizadas na modalidade SAI. O primeiro conteúdo trabalhado nessa modalidade foi mecânica ondulatória, em que foram abordados fundamentos, tais como: a constituição da radiação eletromagnética; comprimento de onda, frequência e energia de radiações e como elas 
se relacionam entre si; dualidade onda-partícula do elétron. O contato prévio com o conteúdo garantiu um tranquilo desenvolvimento dos conceitos em sala de aula. Algumas intervenções pontuais foram necessárias, mas foram efetivas em um curto espaço de tempo. Nos exercícios propostos envolvendo cálculos, observou-se uma plena facilidade por todos.

De forma similar, o contato prévio com os conteúdos de estequiometria e equilíbrio químico permitiu que somente dúvidas pontuais demandassem intervenção do professor. Pequenas introduções nas estratégias de resolução de problemas foram suficientes para o bom desenvolvimento da turma. O mesmo também foi observado quanto aos trabalhos envolvendo ligações químicas, em que ficou latente a dificuldade do grupo em transpor a barreira de conceitos clássicos de ligações, o que foi superado no encontro presencial.

O último conteúdo trabalhado foi o de cinética química. O que se propôs foi a abordagem de fundamentos, tais como: conceito geral de cinética química; velocidade de reação; ordem de reação; métodos de determinação da ordem de uma reação. Considerando que o tempo disponível para a abordagem desses pontos foi de uma semana, contando o período de trabalho em casa e a aula presencial, a avaliação que restou ao final foi positiva. O grupo fez o contato com o conteúdo por intermédio de literaturas e materiais sugeridos e disponibilizados, chegando em aula com os conceitos bastante solidificados. A busca de interpretação por um ângulo matemático ficou bastante nítida. Propôs-se e trabalhou-se presencialmente o uso do método gráfico para a verificação da ordem de uma reação, o que foi recebido e desenvolvido com certa facilidade ao final do processo.

No método SAI, devido ao fato das ações que ocorrem em sala de aula e fora dela serem invertidas, as discussões e compreensão do conteúdo são protagonizadas pelo aluno na presença do professor mediador, enquanto a construção de conhecimentos, por meio da teoria, acontece fora do ambiente educacional. Nesse ponto, não se pode deixar de considerar os apontamentos de Freire (2011), de que o conhecimento não se transfere, e, na verdade, sua produção ou construção deve ser consequência do ato de ensinar. Nesse sentido, o modelo SAI mostrou-se bastante promissor na tentativa de transformação do aluno em um sujeito crítico e autônomo, capaz desenvolver estratégias para melhorar a sua aprendizagem.

É importante salientar que a preparação do aluno em casa deve ser pensada estrategicamente pelo professor, o qual deve propor literatura (física e/ou digital) e arquivos de mídia (videoaulas, documentários, podcasts), juntamente com um roteiro 
claro com o cronograma das tarefas. Esse último, com base nos resultados desta experiência, entende-se como fundamental para o processo, visto que serve para um direcionamento - um mapa - para o desenvolvimento do aluno fora da sala de aula. No caso da disciplina, objeto deste estudo, as recomendações de literatura e mídias seguiram sempre com um roteiro organizado com estrutura e sequência que favorecessem e norteassem as atividades do aluno em casa. Na aula, o roteiro era debatido com outros pontos que surgiam ou eram propostos pelo professor como problema. Eis um ponto importante a ser enfatizado: o professor precisa pensar e planejar cuidadosamente as atividades do aluno fora da sala de aula, para que a aprendizagem seja facilitada e seu desenvolvimento, seja efetivo.

Na presente experiência, observou-se que a principais vantagens da aplicação deste método foram: ( $i$ ) promoção de interações significativas entre professor e alunos, (ii) mudança de postura dos estudantes, que passaram a ser "discentes ativos" e (iii) formação de um discente melhor preparado para atuar na resolução de problemas. Resultados previamente publicados na literatura demonstram que, mesmo no modelo tradicional de ensino, as ações com maior índice de retenção do conhecimento são aquelas em que o estudante adota uma postura participativa e ativa (SCHNEIDERS, 2018), tais como se preconiza no método da SAI.

Em sala de aula trabalhou-se da seguinte forma: inicialmente uma abordagem exploratória era efetuada, com o propósito de verificar o quão a turma conseguiu se apropriar dos conteúdos propostos e como foram as respectivas concepções de conhecimentos. A partir daí, os discentes eram instados a reportar as suas experiências da semana e, então, uma conversação era estabelecida. Cada discente expunha as suas percepções, dificuldades e facilidades, além das respostas ao questionário criado para o conteúdo em foco. Os relatos e respostas eram confrontados e aqueles discentes que não apresentavam dificuldades com o tema eram instigados a ajudar aqueles que não conseguiram evoluir no conteúdo. Ao final, restando algum ponto nebuloso, o professor intervia diretamente, ajudando nas dúvidas remanescentes. Além disso, novas demandas eram propostas na aula, seguindo o mesmo roteiro, de tentativa de resolução em grupo, em que aqueles que resolviam com facilidade ajudavam aos demais que eventualmente apresentavam dificuldades. Tal dinâmica se dava em aula com a mediação do professor.

É imperativo deixar claro que a metodologia aqui relatada não deve ser confundida com as práticas de seminários muito recorrentes, sobretudo, em programas de pós-graduação. Nessa perspectiva, de modo geral, a aula tradicional é substituída 
pela apresentação de seminários e debates entre os pares. Embora se afastando um pouco da audiência cativa atrelada ao protagonismo do docente e do caráter de aluno passivo, essa prática está intimamente ligada ao modelo convencional de ensino, visto que o aluno trata de preparar somente o seu material que será apresentado em aula. Ou seja, o aluno se ocupa fora da sala de aula apenas com um fragmento do que será apresentado por ele. Fora disso, os demais conteúdos, embora não sendo ministrados pelo professor, lhes chegarão da mesma maneira que em uma aula tradicional.

O estudo em casa, ou em local que o valha, é uma forma de diminuir a falta de atenção às particularidades de cada indivíduo, inerentes ao sistema convencional de ensino, em que o aluno em sala de aula é um elemento dependente de aprendizagem passiva e ao professor torna-se impraticável o atendimento às demandas individuais. No entanto, uma vez que o aluno recebe uma sequência estratégica de um roteiro de estudos, com os materiais necessários para a sua aprendizagem ativa, ele terá a autonomia em relação ao tempo, intensidade, horário e método de aprendizagem. Este fato é o que lhe ajudará a encontrar as melhores condições para o desenvolvimento de conhecimento e construção autônoma de sua aprendizagem.

Como ponto crítico da aplicação do modelo SAI, pode-se citar que é necessário que os discentes estejam efetivamente engajados e comprometidos com a proposta. A ausência desses fatores faz com que o método não funcione totalmente, uma vez que essas características são requisitos básicos para que o aluno tenha consciência de seu papel como protagonista do processo de aprendizagem e, consequentemente, leia e faça revisões dos materiais disponibilizados pelo professor previamente ao encontro em sala de aula. Apresentada a percepção docente sobre a SAI, na próxima seção, o foco será a percepção dos alunos a respeito da metodologia.

\section{A percepção dos alunos sobre a SAI}

A metodologia SAI está posta como um desafio para os docentes, porém, também o é para os discentes. No caso deste trabalho, o antagonismo esperado mediante uma nova forma de ensino foi mínimo, o que facilitou o desenvolvimento inicial das atividades. Essa abertura e flexibilidade demonstradas pelo grupo de alunos, em grande parte, podem ser atribuídas ao fato de ser um grupo formado majoritariamente por licenciados. 
Conforme exposto no tópico anterior, os alunos vinham para as aulas presenciais para discutir e sanar suas dúvidas em relação aos seus estudos previamente realizados, por meio do material fornecido pelo professor na aula anterior. O professor da disciplina atuou como mediador, no sentido de instigar questões interessantes para provocar discussões, desenvolver o conteúdo, bem como esclarecer dúvidas em relação à troca de informações que surgiram nas aulas.

O contato prévio dos alunos com os conteúdos, com literaturas e mídias sugeridos, resultou que a turma chegava em sala de aula sempre com a concepção central do conteúdo e, muitas vezes, as dificuldades foram sanadas pelos próprios colegas antes da aula presencial, possibilitando intervenções pontuais por parte do professor. Fica claro, portanto, a importância de o aluno buscar o desenvolvimento do conhecimento de forma autônoma, adequando o seu ritmo e modo de conduzir os estudos. Essa flexibilidade tende a deixar mais equânime o processo de ensino e aprendizagem, respeitando as diferenças constitutivas entre os alunos, e contrastando, assim, nesse aspecto em particular, com o modelo convencional de ensino, que tende a padronizá-los na maneira como aprender e nos tempos de aprendizagem.

Com objetivo de avaliar a percepção dos alunos sobre a SAI, ao final da disciplina foi aplicado um questionário (MASSONI; MOREIRA, 2016), com cinco perguntas abertas relacionadas ao tema. Dos 10 alunos participantes efetivamente da disciplina, sete discentes concordaram em responder ao questionário disponibilizado ao término da experiência com a SAI na disciplina de Tópicos em Química.

Figura 1: Síntese das percepções discentes sobre a SAI no questionário

Fonte: dados da pesquisa (2020).

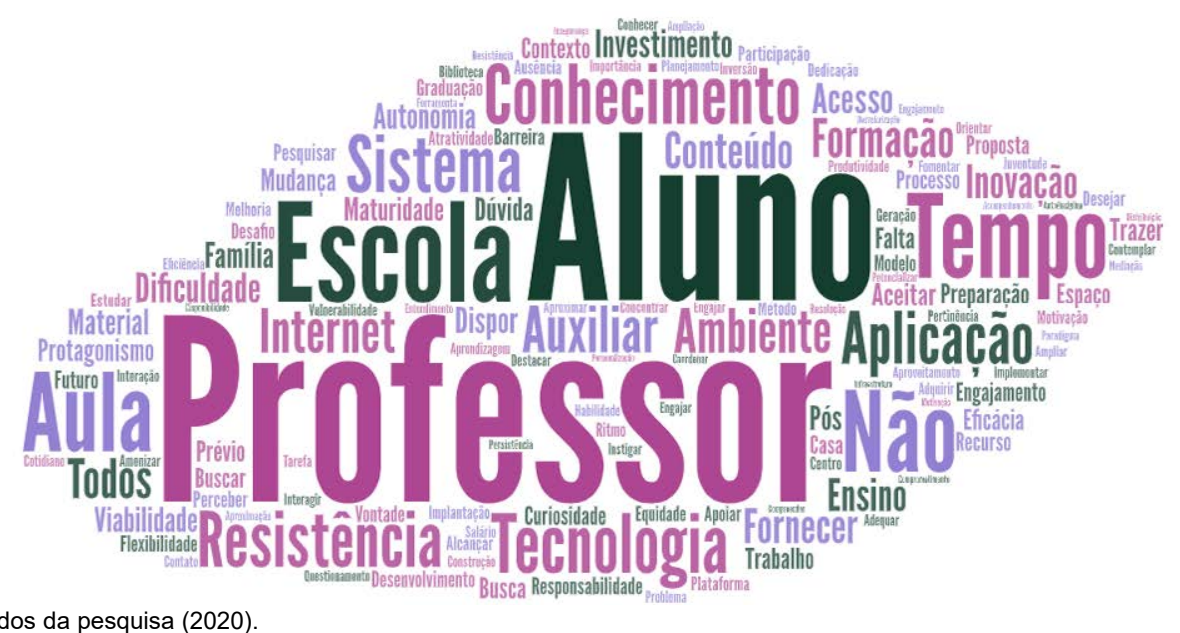


Na Figura 1, elaborada na Plataforma Tagul, são identificadas as palavras que mais representaram o repertório de respostas do conjunto dos discentes ao questionário, seguindo a proposta metodológica conhecida como análise qualitativa por palavras-chave em contexto (LEECH; ONWUEGBUZIE, 2008). A metodologia utilizada para a extração das palavras-chave foi a seguinte: em um primeiro momento, foi efetuada uma análise contextual realizada de maneira manual, ou seja, guiada pelo processo semântico-interpretativo, a partir do qual foram extraídas todas as palavras-chave que ajudaram a compor o conjunto das percepções dos alunos sobre as perguntas efetuadas. Em um segundo momento, todos os verbos extraídos foram colocados no infinitivo e todos os adjetivos foram transformados nos substantivos correlatos (por exemplo, "inovadora" foi convertida em "inovação"), assim como as palavras que estavam no plural foram colocadas no singular e palavras consideradas sinônimas foram agrupadas em uma só, tais como "docente" e "professor", por exemplo.

A nuvem de palavras foi efetivamente composta por substantivos e verbos no infinitivo, com exceção da presença expressiva do advérbio "não" e a manutenção do adjetivo "prévio", o qual no contexto das respostas era associado ao substantivo "conhecimento". A opção analítica por essas classes gramaticais se deu em razão do papel semântico que desempenham no interior dos enunciados (MOURA-NEVES, 2000). Tais ajustes serviram para produzir o agrupamento dos sentidos mobilizados pelas percepções discentes, sem descaracterizar as visões apresentadas pelos alunos. Ao todo, os questionários analisados apresentaram um total de 2.425 palavras, o que representa uma média de 346 palavras por questionário. Considerando essas características, foram levantadas ao todo 350 palavras entre o conjunto de respostas, as quais deram origem à nuvem apresentada, na qual se identificam as palavras que foram mais recorrentes pela apresentação com maior destaque.

Em uma análise holística dos resultados, ao mencionarem aspectos vinculados à SAI, os respondentes trazem um equilíbrio de percepções relacionadas à dimensão docente e à dimensão discente. Quando relacionadas ao discente, aparecem percepções atreladas a vocábulos como motivação, protagonismo, autonomia, papel da família (apoio ao estudo), interesse (ou falta dele por parte do próprio aluno), grau de maturidade e seu nível de engajamento com as atividades. Quando relacionadas ao docente, atrelam-se palavras vinculadas ao investimento por parte da escola, à valorização profissional, à formação continuada para o uso das tecnologias digitais para fins pedagógicos, etc. Identifica-se nas respostas apenas a hipotetização da 
possibilidade de viabilização da SAI na Educação Básica, especialmente na escola pública. Frente a esse possível cenário, evidenciam-se vocábulos como barreira, dificuldade, resistência e a necessidade de recursos (para acesso à Internet, equipamentos e suporte técnico especializado), bem como a presença regular do advérbio de negação "não" (para marcar o que "falta” nas instituições da Educação Básica para tornar a metodologia operacional). Assim, em muitas respostas, percebe-se que a possibilidade da viabilização da SAI como uma metodologia mais condizente ao ensino superior e à pós-graduação, pois os estudantes entendiam, naquele momento, que nesses níveis de ensino há maiores condições conjunturais para que ela seja mais efetiva. Na sequência, serão abordadas as perguntas efetuadas de forma específica e serão detalhados/problematizados alguns desses aspectos até aqui sintetizados de maneira panorâmica.

A primeira pergunta formulada foi: “Qual sua visão a respeito da metodologia Sala de Aula Invertida?”. As respostas denotam que há unanimidade na percepção discente em relação ao potencial do método. Embora não sendo uma metodologia nova, pode ser considerada como inovadora, na perspectiva situada de inovação que se adota neste trabalho (BOHN, 2000; DORNELLES, 2008; IRALA, 2016). Nessa primeira oportunidade em que a vivenciaram, os alunos já demonstraram que veem na SAI uma alternativa para a metodologia de ensino convencional. Entretanto, a sua implementação depende de alguns fatores, como a realidade socioeconômica da unidade de ensino e o comprometimento/engajamento dos alunos e professores envolvidos no processo, os quais se revelam como fortes condicionantes. A resposta de um aluno foi selecionada para exemplificar o entendimento em relação à metodologia, conforme segue: "Compreendo que tal metodologia potencializa o ensino-aprendizagem, pois torna o estudante um ser ativo no processo e retira o "protagonismo" do professor, que se torna um mediador/coordenador das atividades". A resposta em questão reforça o sentimento do aluno sobre tornar-se responsável por seu processo de ensino-aprendizagem. Essa percepção se alinha aos resultados de estudos previamente publicados na literatura (GILBOY; HEINERICHS; PAZZAGLIA, 2015; MCLAUGHLIN, et al., 2014). Esses estudos descrevem que os alunos se tornam mais envolvidos com seu processo de ensino-aprendizagem com a utilização da metodologia SAI em comparação com o método tradicional de ensino.

A segunda questão foi: "Elenque os pontos positivos e negativos da metodologia Sala de Aula Invertida”. Nas respostas, os pontos positivos mais citados foram: o 
contato com o conteúdo previamente à aula (por meio de diversas plataformas); aprendizagem de forma ativa e com mais flexibilidade de tempo; melhor aproveitamento do tempo do professor em sala de aula e, por último, o contato e acompanhamento de tecnologias e metodologias inovadoras de ensino. Já dentre os pontos negativos, observa-se uma unanimidade nas respostas, apontando para: dificuldade de aplicação em comunidades de baixa renda, devido a muitos alunos não terem acesso à Internet; necessidade de equipe diretiva e professores conhecerem bem a metodologia e estarem coordenados/alinhados na sua implantação, e, por último, dificuldade de mudança de paradigma (de aluno passivo para ativo).

Como observado, as respostas dos alunos estão bastante voltadas para o contexto em que estão inseridos no ponto de vista de educacional, considerando suas experiências como professores da educação básica (no caso de discentes com formação inicial no campo das licenciaturas). Na literatura, os problemas (pontos negativos) mais comumente reportados estão relacionados à preparação limitada dos alunos antes do horário das aulas, pois se o aluno não investir tempo para estudar em casa, ele pode não ter um desempenho satisfatório nas atividades em sala de aula e isso pode diminuir as vantagens da SAI (AKÇAYIR; AKÇAYIR, 2018). Uma das vantagens apresentadas como mais significativas desse modelo seria que ele auxilia na melhoria dos desempenhos, o que é um dos elementos-chave da educação de qualidade. Outra vantagem bastante relatada da SAI é a habilidade de usar o tempo em sala de aula de forma mais eficiente (AKÇAYIR; AKÇAYIR, 2018). Ressalta-se que o vocábulo "tempo" recebeu destaque entre os respondentes, normalmente associado ao melhor aproveitamento das vivências em sala de aula, em função do desenho da metodologia SAI, bem como, no que diz respeito ao estreitamento da relação professor-aluno em função das alterações dos tempos didáticos previstos, na medida em que são ampliadas as interações no espaço da sala de aula, em comparação ao modelo tradicional.

A terceira pergunta foi feita para avaliar a percepção dos alunos em termos de viabilidade da metodologia, conforme segue: "Com base na realidade do sistema educacional brasileiro, você considera possível e viável a implementação da Sala de Aula Invertida?". As respostas a essa pergunta foram bastante próximas da pergunta anterior, com grifos de que a implantação da metodologia poderia ser iniciada por escolas com melhores infraestruturas e alunos com mais facilidades em acessar às diferentes plataformas que podem ser usadas para este fim. Em uma resposta, um 
dos alunos menciona: "Na educação básica, vejo mais viável no ensino médio. Sendo que, para tanto, as escolas também devem estar preparadas e promoverem o auxílio devido aos professores”. Já outro destaca: “Considero possível e também viável. Lógico que tal implementação demanda tempo, pois os estudantes estão adaptados ao ensino tradicional de forma que a autonomia em buscar o conhecimento sobre determinado conteúdo ocorre, na grande maioria, de forma passiva”. É evidente o entendimento dos alunos de que o método pode ganhar espaço no sistema educacional brasileiro, contudo percebem que deve ser implementado de forma estratégica e gradativa. É imperativo que outros desafios inerentes ao sistema educacional brasileiro, tais como estrutura curricular pouco atrativa e pouco prática, baixa remuneração e qualificação dos docentes e profissionais da área, ineficiência na administração dos recursos financeiros, somam-se aos pontos críticos para aplicação de metodologias inovadoras de ensino, como entende-se a SAI na discussão proposta por este trabalho.

Também perguntou-se: "Você vê alguma diferença na aplicabilidade da metodologia de Sala de Aula Invertida entre a educação básica, graduação e pós-graduação? Ou seja, em alguma delas seria mais viável que a outra?”. Em síntese, as respostas concordam entre si, apontando que a metodologia pode ser aplicável em qualquer dos níveis. Contudo, na graduação e pós-graduação os alunos destacaram que haveria maior maturidade e comprometimento dos acadêmicos, promovendo melhores resultados. A inclinação à adesão do método a partir da graduação e pós-graduação apresenta, a priori, maiores facilidades, tais como aceitação, flexibilidade e possibilidade de maior engajamento dos alunos, por se tratar de níveis superiores de educação. Esse resultado segue a tendência apresentada na literatura, que demonstra que $80 \%$ dos estudos são conduzidos no ensino superior (AKÇAYIR; AKÇAYIR, 2018). Nesse sentido, a pesquisa publicada por Fielden, Rico e Naranjo (2020) indica que o nível de maturidade dos alunos é uma questão importante, já que discentes menos maduros podem não conseguir lidar com uma aprendizagem de natureza mais autônoma, o que pode comprometer a adoção da metodologia SAI.

Por fim, perguntou-se: "No seu entendimento, quais seriam os fatores e responsáveis pela viabilização da metodologia de sala de aula invertida no sistema educacional brasileiro?”. A grande maioria das respostas aponta em primeiro lugar para a necessidade de o professor estar capacitado, conhecendo bem a metodologia e tendo suas ações respaldadas pela equipe diretiva. Em segundo lugar, observou-se a importância da disponibilidade de ferramentas para o seu desenvolvimento. 
Alguns apontam também a importância do comprometimento da família para ajudar no regramento e adaptação do aluno ao novo modelo de ensino, no qual o professor deixa de ser a peça central do processo. Adicionalmente, os alunos explicaram em sala de aula que a experiência foi válida, que conseguiram desenvolver sua aprendizagem em relação aos conteúdos de Química e que, por esse motivo, entendem que a metodologia pode ser utilizada por outros professores nos níveis de ensino mencionados. Contudo, os alunos enfatizaram que é necessário alto nível de comprometimento para a realização do estudo prévio, antes da aula presencial. Nesse sentido, entende-se que é preciso investir em também proporcionar espaços formativos que auxiliem na gestão do tempo por parte dos estudantes.

\section{Considerações finais}

Na turma de Especialização em Ciência e Tecnologia, foco deste relato, a aplicação do método SAI foi satisfatória (ainda sobre a aplicabilidade metodológica, entende-se, por fim, que ela é sempre reconstruída na/pela experiência). Apesar de, algumas vezes, os alunos sentirem-se reticentes em relação as suas posições de protagonistas, eles tiveram êxito nas leituras prévias e conseguiram discutir e ampliar interações com colegas e professores. As respostas obtidas, por meio da aplicação do questionário, reforçam a ideia dos alunos de que a metodologia é eficiente e que pode ser aplicada no sistema educacional brasileiro, sendo na visão apresentada por eles, melhor aproveitada na graduação e pós-graduação (especializações, mestrados e doutorados), em que se espera mais maturidade por parte dos discentes, permitindo a utilização de metodologias inovadoras que demandam alto grau de comprometimento e responsabilidade. É válido mencionar que a construção progressiva desse comprometimento também depende das estratégias adotadas pelos docentes.

Com base em como se desenvolveram as aulas presenciais e também no desempenho dos alunos em sala de aula, ficou clara para o professor a diferença do impacto da SAI em comparação aos métodos convencionais antes utilizados. Embora eventualmente não tenham conseguido desenvolver um conhecimento apropriado acerca do conteúdo proposto, os alunos buscaram compreender e aprender a respeito. Por conta disso, na aula contava-se com dúvidas claras e focadas, o que facilitou o debate e a busca por respostas satisfatórias junto aos pares e ao professor. 
A tendência para a autonomia do aluno, tornando-o sujeito ativo no processo de sua aprendizagem, assim como a ruptura do paradigma do modelo convencional, em que professor expõe e aluno observa, parecem ser os principais fatores que tornam a SAI um modelo eficiente e atrativo. No entanto, é importante deixar claro que tra-balhar com essa metodologia, para além da maturidade e compromisso dos alunos, exige um alto nível de entrega e comprometimento do docente, pois juntamente com a preparação de cada aula - o que também ocorre no modelo convencional - será necessária a preparação das atividades extraclasse, que antecederão a aula presen-cial. Por tanto, para o sucesso do processo, essas atividades a serem desenvolvidas previamente à aula devem ser organizadas de forma estratégica, de tal modo que facilite o desenvolvimento autônomo do aluno através da construção de um design adequado das tarefas a serem realizadas e a indicação de materiais em multiforma-tos (textos, áudios, vídeos, etc.). Isso, por vezes, não será fácil e demandará tempo e dedicação extras por parte do professor em comparação ao modelo tradicional de ensino. Esse elemento não pode ser desconsiderado no desenho metodológico, pois a gestão do tempo do docente também é uma peça-chave para que se difundam e se estabeleçam metodologias como a SAI nas diferentes instituições de ensino e docentes que ainda a desconhecem.

Os resultados oriundos deste relato apontam que os alunos entenderam que seria possível e viável a implementação do modelo SAI no sistema educacional brasileiro, a partir de suas percepções oriundas de suas experiências locais e situadas. Contudo, é preciso uma disseminação dos fundamentos da metodologia, antes da execução do processo, de modo a se estabelecerem antecipações e ações imediatas frente aos possíveis problemas já conhecidos por outras experiências e pesquisas relatadas nos diversos contextos educacionais em que já há uma tradição de sua implementação. É importante ressaltar o caráter situado de cada contexto institucional e o quanto a inovação educativa é condicionada por esse caráter. As metodologias se "movimentam" a partir das ações dos indivíduos que as implementam e, a cada experiência, novas reflexões, muitas delas não previstas na literatura da área, emergem como elementos imprevistos, os quais conduzem para a promoção de estratégias também situadas e criativas por parte de cada professor, em contexto. Nesse sentido, a formação continuada dos professores, mencionada como muito importante pelos respondentes, também é um ponto crucial nesse caminho de mudança. Dentro do campo da 
formação continuada, é importante ressaltar que advogamos a preferência por modelos horizontais e contínuos, pois eles podem ser mais efetivos do que as tradicionais formações de natureza verticalizada, como as palestras pontuais, apenas com participantes externos, que não vivenciam a cultura institucional daquele contexto.

Como perspectivas para trabalhos futuros, pretende-se utilizar a metodologia SAI e observar os resultados em outra disciplina de pós-graduação lato sensu, voltada a conteúdos avançados de Química e não introdutória, como é o caso da disciplina de Tópicos em Química. Com essa ação, pretende-se contribuir na desconstrução de paradigmas no que se refere ao "engessamento" da utilização da metodologia de ensino tradicional para disciplinas das áreas das ciências naturais e exatas (tais como Física, Química, Matemática) e evidenciar, assim quais estratégias são possíveis para enfrentar os desafios correntes nessas áreas.

Por último, é importante mencionar que o ano de 2020, a partir das diretrizes sanitárias de restrição e distanciamento social em função da COVID-19, impôs, obrigatoriamente, um novo cenário educacional, o qual, até o momento em que esta experiência havia sido executada, não se pensava. Se na visão dos atores do processo implicados nesta experiência um modelo como a SAI era visto como mais viável na Graduação e na Pós-Graduação, devendo ser adotado gradativamente e com a presença de um conjunto de condicionantes relacionados ao papel dos gestores educacionais em investimentos na formação continuada e na aquisição de equipamentos para as instituições, entre outros aspectos, tais como a infraestrutura, quando se referiam à Educação Básica, tem-se, agora, outra configuração, que traz, de forma ostensiva, novas perspectivas de pesquisa e desafios diários para os professores de todos os níveis de ensino e para os estudantes de quaisquer faixas etárias.

\section{Flipped classroom: teacher and students perceptions from an experience report of chemistry classes in the graduate degree course}

\section{Abstract}

The use of active methodologies has been widely discussed at all levels of education as a tendency to overcome classes in an exclusively transmissive format and focused on the teacher, to give protagonism to students during the didactic development. Criticism of traditional teaching models is not new and has been widely discussed by the academic community; however, in 
addition to the theoretical model mobilized when a teacher is willing to adopt an active methodology, whatever it may be, it becomes necessary to contrast the adopted model to what, in fact, it is possible to operationalize in each specific context, with its characteristics, expectations and difficulties. It's mean that for each new teaching experience with the use of the adopted methodology, other aspects not foreseen by the theoretical model are (re)dimensioned in the light of teaching practice. In this sense, this work is configured as an experience report regarding the use of the Flipped Classroom (SAI, in portuguese) methodology, in the course of Topics in Chemistry, in a Graduate Program Degree in Exact Sciences and Technology offered at a public university in Southern Brazil. The text of the report presents two focuses: in the first, the teaching framework about the experience and, in the second, the students' perception of the SAI model, from a questionnaire with open questions, answered to the end of the course. The results show that, in the context in question, a Graduate Program Degree, gains in student learning were evidenced and the occasional difficulties in understanding the content were equalized during the face-to-face classes. In turn, some students, when evaluating the transposition of SAI, especially for the context of Primary and Secondary Schools, although they show the advantages of the model, they also point out some challenges, with need to be addressed or minimally predicted during each teaching experience, in order to always understand it in a situated view.

Keywords: active methodologies; flipped classroom; Chemistry teaching; perceptions.

\section{Referências}

AGUIRRE-AGUILAR, Genaro. El estudiante y la configuración del aula activa: Itinerario, aprendizajes e investigación. Alteridad, 15(2), p. 161-173, 2020. https:// doi.org/10.17163/alt.v15n2.2020.02

AKÇAYIR, Gökçe; AKÇAYIR, Murat. The flipped classroom: A review of its advantages and challenges. Computers \& Education, v. 126, p. 334-345, 2018.

BACICH, Lilian; MORAN, José. Metodologias ativas para uma educação inovadora: uma abordagem teórico-prática. Porto Alegre: Penso, 2018.

BERBEL, Neusi. As metodologias ativas e a promoção da autonomia de estudantes. Semina: Ciências Sociais e Humanas, Londrina, v. 32, n. 1, p. 25-40, jan./jun. 2011.

BERGMANN, Jonathan; SAMS, Aaron. Sala de aula invertida: uma metodologia ativa de aprendizagem. Rio de Janeiro: LTC, 2016.

BERGMANN, Jonathan; OVERMYER, Jerry; WILIE, Brett. The Flipped Class: What It Is and What It Is Not. 2012. Disponível em: http://www.thedailyriff.com/articles/the-flippedclassconversation-689.php. Acesso em: 12 ago. 2019.

BEZERRA, Edson. A educação e as novas tecnologias. São Paulo: WebArtigos, 2007. Disponível em: < http://www.webartigos.com/artigos/a-educacao-e-as-novastecnologias/3050>. Acesso em: 07 set. de 2015 .

BISHOP, Jacob; LOWELL, Verleger, MATTHEW, Alan. The Flipped Classroom: A Survey of the Research. In: ASEE Annual Conference \& Exposition, 120., 2013, Atlanta. Anais...Washington DC, American Society for Engineering Education, 2013. p. 1-18. Disponível em: https://www.asee. org/public/conferences/20/papers/6219/download. Acesso em: 08 set. 2019.

BIZOLATTI, Aline da Silva; NETO, João Coelho. Sala de Aula Invertida: possíveis aproximações para o ensino da Matemática. Revista Thema, v. 15, n. 3, p. 848-859, jun. 2018. 
BOHN, Hilário Inácio. Maneiras inovadoras de ensinar e aprender: a necessidade de (re)construção de conceitos. In: LEFFA, Vilson (org.). O professor de línguas estrangeiras: construindo a profissão. Pelotas: Educat, 2001, p.115-124.

CAMARGO, Fausto; DAROS, Thuinie. A sala de aula inovadora: estratégias pedagógicas para fomentar o aprendizado ativo. Porto Alegre: Penso, 2018.

CARBONELL, Jaume. Pedagogías del siglo XXI. Barcelona: Octaedro, 2015.

DORNELLES, Clara. A gente não quer ser tradicional, mas...como é que faz, daí? A inovação curricular e o debate popularizado sobre língua portuguesa e ensino. 2008. 169p. Tese (Doutorado em Linguística Aplicada), Instituto de Estudos da Linguagem, Universidade Estadual de Campinas, Campinas, 2008.

FERNANDES, Domingos. Avaliações externas e aprendizagens dos alunos: uma reflexão crítica. Linhas Críticas, v. 25, p.74-90, 2019. https://doi.org/10.26512/lc.v25i0.24579

FIELDEN BURNS, Laura; RICO, Mercedes; NARANJO, Maria José. Flipped Classrooms: Making them Work for Foreign Language Students. Diacrítica, v. 34, n. 1, p. 336-354, 2020.

FREIRE, Paulo. Pedagogia da autonomia: saberes necessários à prática educativa. São Paulo: Paz e Terra, 2011.

GILBOY, Mary Beth, HEINERICHS, Scott; PAZZAGLIA, Gina. Enhancing Student Engagement Using the Flipped Classroom. Journal of Nutrition Education and Behavior, 47, 109-114, 2015.

INGOLD, Tim. The perception of the environment: essays of livelihood, dwelling and skill. Londres/ Nova York: Routledge, 2000.

IRALA, Valesca. Inovação na formação de professores de espanhol: a experiência em um curso de Letras/línguas adicionais. In: ERES FERNÁNDEZ, Gretel; BAPTISTA, Lívia; SILVA, Antônio (orgs.). Enseñanza y aprendizaje del español en Brasil: aspectos lingüísticos, discursivos e interculturales. Brasília: Consejería de Educación de la Embajada de España, 2016. p. 171-184.

LEECH, Nancy; ONWUEGBUZIE, Anthony. Qualitative data analysis: A compendium of techniques and a framework for selection for school psychology research and beyond. School Psychology Quarterly, v. 23, n. 4, p. 587-604, 2008. DOI: https://doi.org/10.1037/1045-3830.23.4.587.

LIMA-JÚNIOR, Cláudio Gabriel et al. Sala de Aula Invertida no Ensino de Química Planejamento, Aplicação e Avaliação no Ensino Médio. REDEQUIM - Revista Debates em Ensino de Química. v. 3, n. 2, p. 119-145, 2017.

LOUREIRO, Cesar Augusto; DELPHINO, Fátima Beatriz. Relato de experiência com aula invertida em curso de especialização. Posgere, v. 1, n. 2, mai.2017, p. 172-184. Disponível em: http:// seer.spo.ifsp.edu.br/index.php/posgere/article/view/102/pdf. Acesso em: 08 set. 2019.

MACEDO, Kelly Dandara, et al. Metodologias ativas de aprendizagem: caminhos possíveis para inovação no ensino em saúde. Esc Anna Nery, v. 22. n. 3, p. 1-9, 2018.

MARTINS, Luiza Pires Ribeiro. Projeto sala de aula invertida de química: uma proposta de sequência didática sobre equilíbrio químico. Produto educacional (Mestrado) - Centro de Ciências Tecnológicas, Universidade do Estado de Santa Catarina, Joinville, 2018.

MCLAUGHLIN, Jacqueline et al. The Flipped Classroom: A Course Redesign to Foster Learning and Engagement in a Health Professions School. Academic Medicine, v. 89, n. 2, feb. 2014. 
MASSONI, Neusa; MOREIRA, Marco Antonio. Pesquisa qualitativa em Educação em Ciências. São Paulo: Editora Livraria da Física, 2016.

MENDOZA, Juan José. El canon digital: la escuela y los libros en la cibercultura. Buenos Aires: La Crujía, 2011.

MOURA NEVES, Maria Helena. Gramática de Usos do Português. São Paulo: Ed. UNESP, 2000.

OLIVEIRA, Tobias Espinosa; ARAÚJO, Ives Solano; VEIT, Eliane Angela. Sala de aula invertida (flipped classroom): inovando as aulas de Física. Física na Escola, v. 14, n. 2, p. 04-13, 2016.

PAVANELO, Elisangela; LIMA, Renan. Sala de Aula Invertida: a análise de uma experiência na disciplina de Cálculo I. Bolema, Rio Claro (SP), v. 31, n. 58, p. 739-759, ago. 2017.

ROSSIT, Rosana Aparecida Salvador; STORANI, Karin (orgs.). Avaliação nos processos educacionais. São Paulo: Ed. UNIFESP, 2010.

SANT'ANA, Geisa; AMORIM, Fábio Ferreira; MELO, Bárbara de Caldas. Blended Learning e a sala de aula invertida: A experiência do mestrado acadêmico da escola superior de Ciências da Saúde. In: PAN PBL International Conference, 2018, Santa Clara. Conference Proceedings. Santa Clara: Santa Clara University. Disponível em: http://pbl2018.panpbl.org/wp-content/ uploads/2018/02/UMA-PROPOSTA-DE-METODOLOGIA-ATIVA-NA-PO\%CC\%81S-GRADUAC\%CC\%A7A\%CC\%830.pdf. Acesso em: 11 set. 2019.

SCHNEIDERS, Luís Antônio. O método da sala de aula invertida (flipped classroom). Lajeado: Ed. da Univates, 2018.

TALBERT, Robert. Guia para utilização da aprendizagem invertida no ensino superior. Porto Alegre: Penso, 2019.

TUNE, Johnathan; STUREK, Michael; BASILE, David. Flipped classroom model improves graduate student performance in cardiovascular, respiratory, and renal physiology. Adv Physiol Educ, Indianapolis, v. 37, n. 4, p. 316-320, 2013.

VALENTE, José Armando. Blended Learning e as mudanças no ensino superior: a proposta da sala de aula invertida. Educar em Revista, Curitiba, Edição Especial n. 4, p. 79-97. 2014.

VIANNA, Heraldo Marelim. Avaliações nacionais em grande escala: análises e propostas. Estudos em Avaliação Educacional, n. 27, p. 41-76. jan-jun/2003. 